CLINICAL STUDY

\title{
Nationwide trends in surgery and radioiodine treatment for benign thyroid disease during iodization of salt
}

\author{
Charlotte Cerqueira $^{1}$, Nils Knudsen ${ }^{2}$, Lars Ovesen ${ }^{3}$, Peter Laurberg ${ }^{4}$, Hans Perrild ${ }^{2}$, Lone B Rasmussen ${ }^{5}$ \\ and Torben Jørgensen ${ }^{1,6}$ \\ ${ }^{1}$ Research Centre for Prevention and Health, Glostrup University Hospital, Nordre Ringvej 57, Building 84/85, DK-2600 Glostrup, Denmark, \\ ${ }^{2}$ Department of Endocrinology and Gastroenterology, Bispebjerg University Hospital, Copenhagen, Denmark, ${ }^{3}$ Department of Gastroenterology, Slagelse \\ Hospital, Slagelse, Denmark, ${ }^{4}$ Department of Endocrinology, Aalborg Hospital, Aarhus University Hospital, Aalborg, Denmark, ${ }^{5}$ Department of Nutrition, \\ National Food Institute, Technical University of Denmark, Soborg, Denmark and ${ }^{6}$ Faculty of Health Sciences, University of Copenhagen, \\ Copenhagen, Denmark \\ (Correspondence should be addressed to C Cerqueira; Email: chacer01@glo.regionh.dk)
}

\begin{abstract}
Objective: Iodization of salt was introduced in Denmark in 1998 because of mild-to-moderate iodine deficiency (ID). The aim of this study was to analyze the utilization rate of surgery and radioiodine therapy for benign thyroid disorders before and after the introduction of iodization, and to study a possible association between the changes and the raised iodine intake.

Design: A nationwide register study.

Methods: Information on operations and radioiodine treatments for benign thyroid disorders was extracted from nationwide registers in the years 1990 to 2007. Treatment rates are presented for surgery and for radioiodine separately, and as a combined rate, both nationwide and split by the regions of prior mild and moderate ID.

Results: A total of 65605 treatments were identified: 26456 operations and 39149 radioiodine treatments. In the first years of iodization (1998-2000; rate ratio 2000/1997), the combined treatment rate increased with $2.5 \%$ (95\% confidence interval (CI): $-1.8-7.1)$. Split by prior ID level, the increase was seen in the region of moderate ID, but a decrease was seen in the region of mild ID. After 2000, the combined rate decreased, and ended up being 11.1\% (95\% CI: 7.1-15.0) lower in 2007 than before iodization (rate ratio 2007/1997). The changes were primarily due to changes in the use of radioiodine therapy as the surgery rates remained almost constant.

Conclusions: Iodization seemed to be associated with a temporary increase in the utilization rate of surgery and radioiodine therapy in the region of prior moderate ID, probably as a result of treatment of iodine-induced hyperthyroidism, but the rates ended up being lower than before iodization.
\end{abstract}

European Journal of Endocrinology 162 755-762

\section{Introduction}

Iodine fortification of salt has been initiated in many countries in the last decades. The latest estimation by the World Health Organization (WHO) shows that about $70 \%$ of the households throughout the world have access to iodized salt (1). A major argument for increasing the iodine intake by an iodine fortification programme in mildly and moderately iodine-deficient areas is to prevent thyroid growth and autonomy, and thereby goitre and hyperthyroidism (2). A criterion for success of an iodization programme is that fewer persons become patients suffering from iodine deficiency (ID) disorders. Using the words of Delange: '...it has to be clearly understood that the ultimate goal of any program of iodine supplementation is to normalize thyroid function at the individual level. It is not only to organize access to iodized salt nor to increase the urinary iodine' (3). Only a few studies in Europe have analyzed in detail the change in the number of patients being treated in a population before and after an iodization programme (4). In Denmark, there are three main treatment options for an enlarged thyroid gland and/or hyperthyroidism: antithyroid medication, surgery and radioiodine treatment. While levothyroxine therapy is widely used for non-toxic goitre in some European countries, this treatment is rarely used in Denmark (5). On the other hand, radioiodine therapy is widely used for non-toxic goitre in Denmark (5).

In Denmark, iodine fortification was started as a voluntary programme of adding iodine to salt in 1998 (adding 8 p.p.m. iodine to all salt). The fortification was made mandatory in 2000 (adding 13 p.p.m. iodine to household salt and salt used in the commercial production of bread) because of the limited use of iodized salt during the voluntary programme. Studies of 
population groups showed that the prevalence of thyroid enlargement among adults was reduced from $17.6 \%$ before iodization to $10.9 \%$ after iodization, which was estimated by ultrasound (6). The incidence of hyperthyroidism also decreased, although after a modest, temporary increase in the early years after iodization (7). A decrease in the incidence of hyperthyroidism and in thyroid size observed by ultrasound is interesting, but to be clinically relevant, this should lead to a decrease in the number of patients treated. The incident use of antithyroid medication has been analyzed and the results have been published in a previous report, showing similar trends as for the studies of the incidence of hyperthyroidism (8). In this study, we have focussed on the use of surgery and radioiodine treatment and whether iodization of salt affected the frequency of operations and radioiodine treatments for benign thyroid disease in Denmark.

\section{Materials and methods}

\section{Setting}

The Danish population comprises around 5300000 inhabitants. A unique ten-digit identification number, which is assigned to every person in Denmark at birth or immigration, is used in all contacts with public services including hospitals. The identification number facilitates linkage on an individual level and over time, making the use of registers feasible for the evaluation of changes in health care services.

The Danish National Patient Registry has been keeping records on all hospital admissions in Denmark since 1977, and each hospitalization is classified according to the International Classification of Diseases (ICD; until 1994, the ICD-8 and from 1994 the ICD-10 (ICD-9 was never introduced in Denmark)). All operations and most treatments performed are classified according to the National Board of Health's classification of operations and treatments (3rd version in the period 1989-1995 and 4th version in the period 19962007), which are standardized in the Nordic countries. Coding is essential for departments in hospitals as the codes are used in the calculation of productivity, and thereby the financing of the department. The register thus has nationwide coverage and a high validity, especially for surgical procedures (9). Denmark has a tax-financed health care system with free access for all citizens to public hospitals for essential treatments, including operations. The privately financed hospital sector is small, comprising $\sim 1 \%$ of hospital beds in 2001 (10).

\section{Identification of operations}

All hospital admissions in the period 1990-2007 that included one or more codes for operations (resections, lobectomy or total thyroidectomy) on the thyroid gland were studied (Nordic Classification of Surgical Procedures codes: 08 060-08 220 before 1996; BAA20-BAA60 after 1996). Procedures coded with more than one operation code (e.g. lobectomies with resection of the other lobe) for the same person, on the same date, were counted as one operation only. Operations performed up to 3 months prior to or during a hospitalization, classified with a diagnosis of thyroid cancer (ICD codes DC73.9 or 19 399), were excluded in order to analyze the trends in the treatment frequency of benign thyroid disorders only. The yearly number of total thyroidectomies because of thyroid cancer was 95 in 1990, 112 in 1997 and 157 in 2007. Furthermore, 97 operations $(0.37 \%)$ were excluded because the patients did not have a Danish identification number or because of missing information on the place of residency.

\section{Identification of radioiodine treatments}

Departments giving radioiodine treatments are required to report the number of treatments performed (doses given), the average administered activity and whether the treatment is given for benign or malignant disease to the National Institute of Radiation Protection. This registration did not use the Danish identification number until 2004 when radioiodine treatment was assigned a treatment code in the Danish National Patient Registry. Consequently, we were not able to link information on radioiodine treatment on an individual level to other national registers to gain information on residency, sex and age. Instead, information on the location of the hospital treating the patients was used as proxy for residency of patients. According to national regulations, outpatient treatment only includes treatment up to a certain dose of ${ }^{131} \mathrm{I}(600 \mathrm{MBq})$. Fractioned doses to achieve a higher total dosage are rarely given. Thus, in the present study, we considered one dose equivalent to one treatment.

\section{Combined treatment rate}

The choice among the two treatment modalities depends not only on the clinical features but also on the availability and the personal preference of the patient and the physician. There is a known difference among physicians in eastern and western Denmark with regard to the preferences between surgery and radioactive iodine (11). A combined treatment rate was therefore constructed by simply adding the number of radioiodine doses given and the age-adjusted number of operations performed for each year and geographical region to analyze the total treatment activity before and after iodization. 


\section{Iodine intake}

Iodine intake is lower in the western part of Denmark than in the eastern part, primarily because of a difference in the level of iodine in ground water (12). Prior to fortification, the median urinary iodine excretion in spot urine samples was $45 \mu \mathrm{g} / \mathrm{l}(54 \mu \mathrm{g} / \mathrm{l}$ among persons taking iodine-containing supplements daily) in the city of Aalborg, in the western part of the country, and it was $61 \mu \mathrm{g} / \mathrm{l}(68 \mu \mathrm{g} / \mathrm{l}$ among persons taking iodine supplements daily) in Copenhagen, in the eastern part of the country. Of the investigated persons, $34.5 \%$ took iodine-containing supplements daily (13). Thus, the two cities were considered respectively moderately and mildly iodine-deficient according to the criteria outlined by WHO (1). After fortification, median urinary iodine excretion rose to $86 \mu \mathrm{g} / \mathrm{l}$ in Aalborg and to $99 \mu \mathrm{g} / \mathrm{l}$ in Copenhagen among persons not taking iodine-containing supplements, and to 93 and $108 \mu \mathrm{g} / \mathrm{l}$ respectively when including the $29 \%$ of the investigated persons taking iodine-containing supplements (14). The iodine intake in Aalborg and Copenhagen represents the geographical difference in iodine intake between the western and the eastern parts of Denmark before iodization of salt (15).

\section{Statistical methods}

For calculations, Denmark was divided into two regions, eastern and western Denmark, through the Great Belt.
Region of residence/treatment was used as a proxy for iodine status. The population comprises about 2950000 inhabitants in the western region and about 2350000 inhabitants in the eastern region.

Data processing and statistical analyses were performed with SAS 9.2 statistical software (SAS Institute Inc., Cary, NC, USA). To adjust for changes in the mean age of the Danish population, over time, rates were standardized, when possible, to the age composition of the Danish population in the year 2000.

The yearly rates were compared with the rate before iodization (1997) using Poisson regression to model the association between treatment utilization and calendar year. The level of significance was set to $5 \%$.

The Danish Data Protection Agency approved the present study (no. 2007-58-0015). No ethical approval is required for retrospective registry studies in Denmark.

\section{Results}

A total of 65605 treatments for benign thyroid diseases were identified: 26456 operations and 39149 treatments of radioiodine (Table 1 ).

The nationwide, combined treatment rates (surgery + radioiodine) showed an initial increase from 1990 to 1997. From 1997, the year before the introduction of the iodization programme, to 2000, the rates still increased but with a lower gradient. This increase amounted to a $2.5 \%$ (95\% confidence interval

Table 1 Number and characteristics of operations and radioiodine treatments used for benign thyroid diseases in Denmark from 1990 to 2007.

\begin{tabular}{|c|c|c|c|c|c|}
\hline \multirow[b]{2}{*}{ Year } & \multicolumn{4}{|c|}{ Operations } & \multirow{2}{*}{$\begin{array}{c}\text { Radioiodine } \\
\text { treatments } \\
n \\
n\end{array}$} \\
\hline & $n$ & $\begin{array}{l}\text { Percentage of } \\
\text { lobectomies or } \\
\text { solely unilateral } \\
\text { resections }^{\mathrm{a}}\end{array}$ & $\begin{array}{c}\text { Female to male ratio } \\
\left(n_{\text {female }} / n_{\text {male }}\right)\end{array}$ & $\begin{array}{c}\text { Mean age of } \\
\text { patients (range) }\end{array}$ & \\
\hline 1990 & 1530 & - & $5.1(1281 / 249)$ & $45.8(0-85)$ & 1175 \\
\hline 1991 & 1455 & - & $5.1(1216 / 239)$ & $45.6(15-88)$ & 1354 \\
\hline 1992 & 1503 & - & $4.7(1238 / 265)$ & $46.3(13-87)$ & 1592 \\
\hline 1993 & 1540 & - & $5.6(1305 / 235)$ & $45.5(13-87)$ & 1688 \\
\hline 1994 & 1393 & - & $5.2(1168 / 225)$ & $46.0(12-87)$ & 2113 \\
\hline 1995 & 1284 & - & $4.4(1047 / 237)$ & $45.8(9-89)$ & 2169 \\
\hline 1996 & 1419 & 64.2 & $5.0(1183 / 236)$ & $46.0(3-88)$ & 2459 \\
\hline 1997 & 1458 & 64.5 & $4.9(1211 / 247)$ & $46.7(6-91)$ & 2517 \\
\hline $1998^{b}$ & 1472 & 63.4 & $4.7(1213 / 259)$ & $46.3(6-86)$ & 2547 \\
\hline 1999 & 1498 & 66.3 & $4.7(1237 / 261)$ & $46.5(6-85)$ & 2582 \\
\hline $2000^{c}$ & 1568 & 66.0 & $4.6(1288 / 280)$ & $46.7(7-100)$ & 2570 \\
\hline 2001 & 1466 & 63.0 & $4.7(1209 / 257)$ & $47.0(8-92)$ & 2677 \\
\hline 2002 & 1441 & 62.6 & $4.8(1194 / 247)$ & $47.7(8-86)$ & 2615 \\
\hline 2003 & 1470 & 65.4 & $5.0(1227 / 243)$ & $47.5(12-88)$ & 2481 \\
\hline 2004 & 1439 & 63.9 & $4.2(1161 / 278)$ & $48.0(8-88)$ & 2328 \\
\hline 2005 & 1533 & 64.5 & $4.8(1268 / 265)$ & $48.9(8-89)$ & 2114 \\
\hline 2006 & 1517 & 65.9 & $4.6(1248 / 269)$ & $49.0(8-92)$ & 2015 \\
\hline 2007 & 1560 & 66.8 & $4.4(1270 / 290)$ & $50.2(5-95)$ & 2153 \\
\hline
\end{tabular}

a 1990-1995: Codes do not allow separation of solely unilateral surgery and other procedures. 1996-2007: Nordic Classification of Surgical Procedures code: either BAA20 or BAA40.

binitiation of voluntary iodization.

Initiation of mandatory iodization. 
(CI): - 1.8-7.1) higher rate in 2000 than in 1997. From 2000, the rates declined, followed by a small increase in 2007, and ended up being $11.1 \%$ (95\% CI: 7.1-15.0) lower in 2007 than the rate in 1997. When splitting the combined treatment rates by the two regions, the rates were very equal in the early years (1990-1995), after which they started to diverge (Fig. 1B). In the eastern part of the country, the treatment rate decreased, and it decreased 13.6\% (95\% CI: 7.1-19.6) from 1997 to 2007. In the western part of the country, treatment intensity increased with a peak in 2000/2002, followed by a decline. From 1997 to 2002 , this temporary increase in the western part of the country amounted to $12.4 \%$ (95\% CI: $6.4-18.6$ ). However, the rate in 2007 ended up being 9.5\% (95\% CI: 4.2-14.5) lower than the rate before the iodization (1997).
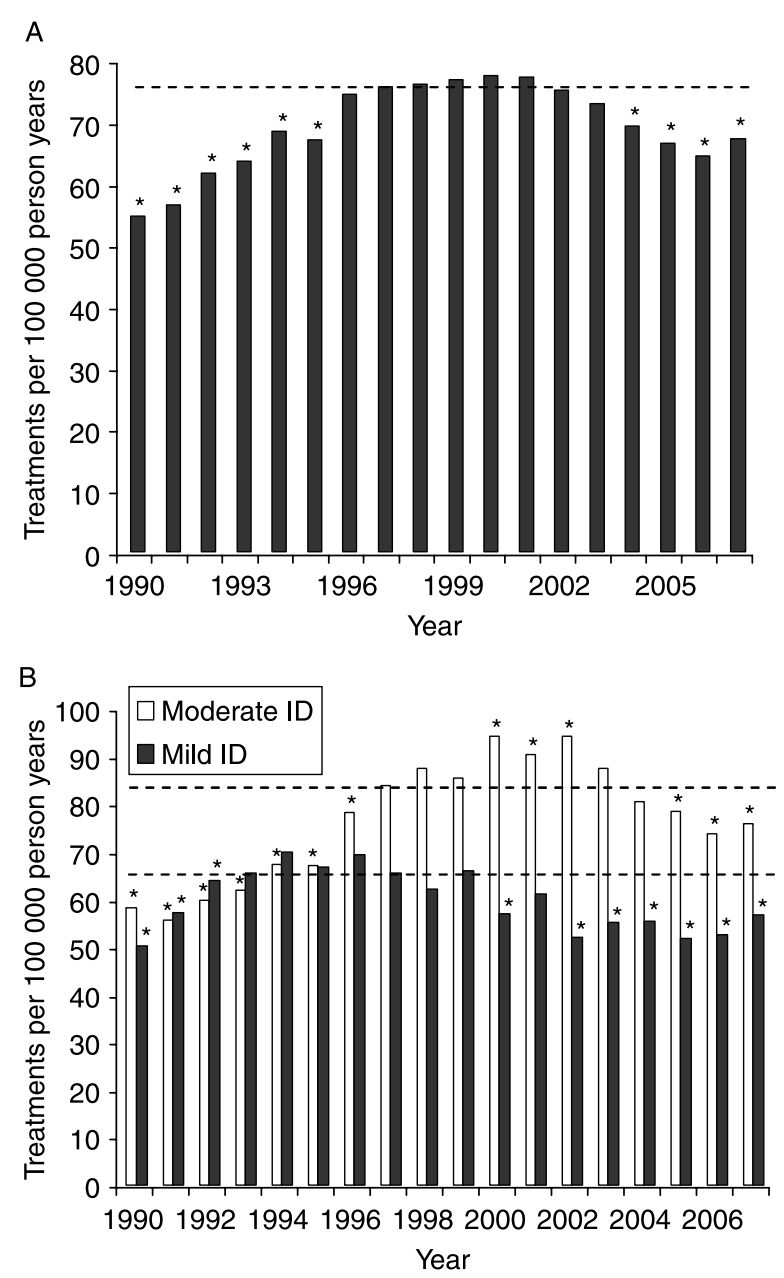

Figure 1 Combined rates of surgery and radioiodine. (A) Nationwide combined annual rates. (B) Combined annual rates split by region of prior mild or moderate iodine deficiency (ID). The rate in 1997 (the year before the introduction of iodization of salt) has been marked by a broken line for easier comparison. *Significant difference between the rate in the investigated year and the rate in $1997(P<0.05)$.
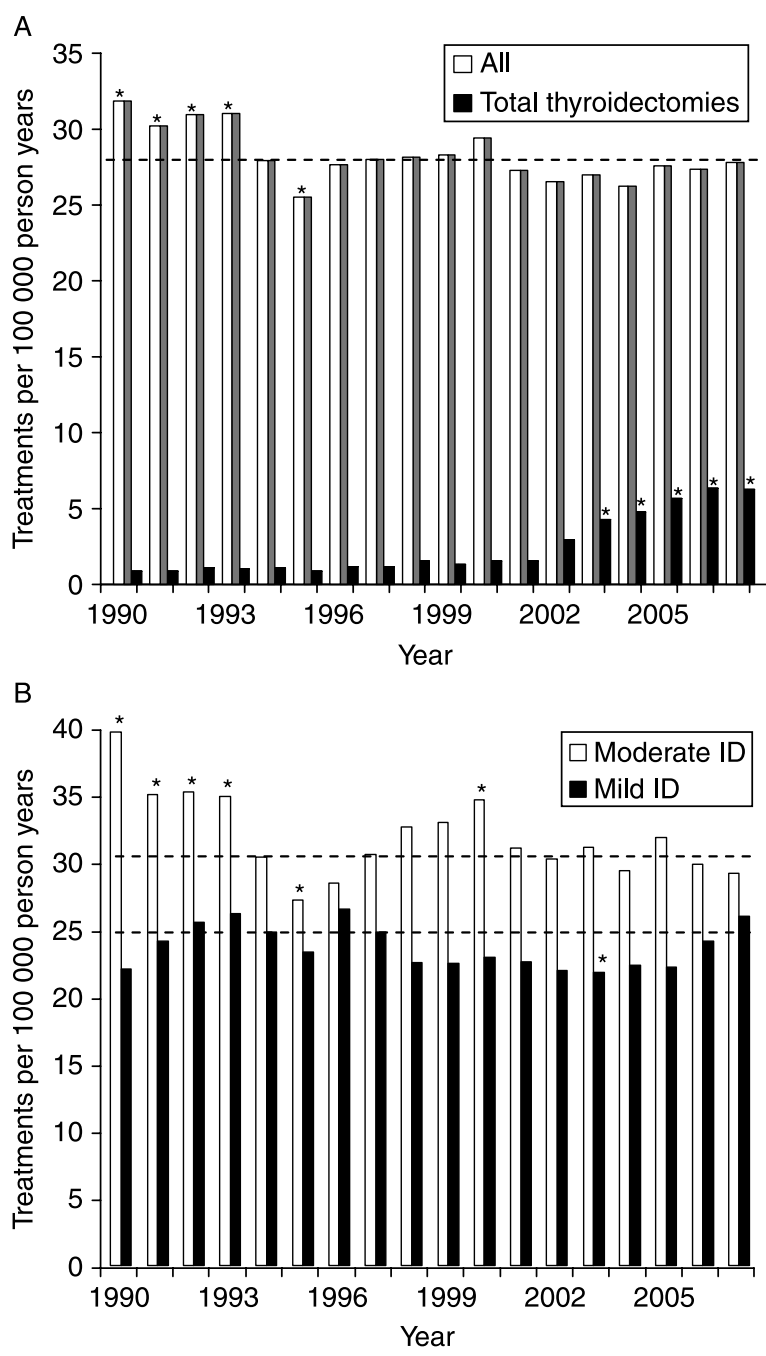

Figure 2 Surgery. (A) $\square$ Nationwide annual rates of all the performed operations for benign thyroid diseases, including total thyroidectomies. Annual rates of total thyroidectomies. (B) Annual rates of performed operations for benign thyroid diseases split by region of prior mild or moderate iodine deficiency (ID). The rates are adjusted according to the age composition of the population in Denmark in the year 2000. The rate in 1997 has been marked by a broken line for easier comparison. *Significant difference between the rate in the investigated year and the rate in $1997(P<0.05)$.

The numbers of operations performed, including all types of benign thyroid surgeries, were very stable during the 18 years of the study period (Table 1). However, when looking at the age-adjusted rates (Fig. 2A), there was a significant trend for an annual decrease of $0.75 \%$ in the rates (95\% CI: $0.3-1.2)$. No statistically significant changes were seen in the use of surgery after iodization when compared with the rate of surgery in 1997. The type of operation performed for benign thyroid disease changed in this study period. The percentage of total thyroidectomies performed for 
benign thyroid diseases increased from $2.8 \%$ of all operations in 1990 , over $4.4 \%$ in 1997 , to $22.9 \%$ in 2007. Still, the percentage of operations performed only on one side of the gland (typically in case of a solitary nodule where malignancy cannot be ruled out by biopsy) remained almost the same (Table 1).

Split by regions, the surgery rates were higher in the western part of Denmark than in the eastern part in all the 18 years studied (Fig. 2B). The rates also seem to vary more in the western part of Denmark than in the eastern part, showing a small temporary increase after the introduction of iodization, even though the variation from the rate in 1997 in most of the years was not statistically significant. The variation tended to be larger before than after the iodization. A statistically significant trend for an annual decrease was found in the western region (1.0\% (95\% CI: $0.3-1.7)$ ), but not in the eastern region $(0.3 \%$ (95\% CI: $-0.3-0.9))$.

The nationwide rates for radioiodine treatment have changed much more than for surgery. The use of radioiodine increased throughout the 1990's, reaching a peak in 2001, followed by a decline (Fig. 3A). When splitting the use of radioiodine by region, two different patterns emerged (Fig. 3B). In the eastern region, the use of radioiodine increased until 1994, followed by a small decline in the treatment rate until 1997/98 and a larger decline around 2000 and 2002. In the western region, the increase lasted until 2002 and reached a 20\% higher rate than in 1997 (95\% CI: 12.2-28.3), followed by a decline ending up $12.3 \%$ lower than in 1997 (95\% CI: 5.8-18.4).

\section{Discussion}

In this study, covering 8 years before and 10 years after iodization of salt, we found that the combined rate of radioiodine and surgery for benign thyroid diseases decreased in the period after the introduction of iodization of salt. This occurred after a temporary increase in the area with prior moderate ID. The changes were mainly due to changes in the use of radioiodine, as the rates of surgery were more stable.

We have no knowledge of similar nationwide studies assessing changes in radioiodine treatment and surgery during iodine fortification.

The increase in the use of radioiodine from 1990 to 1997, which is transferred to an increase in the combined rates in the same years, makes it plain that the changes in treatment intensity cannot be explained only by iodization, and it could be reasonably stated that a causal relationship between the raised iodine intake and the trends in the utilization rates of surgery and radioiodine is not proved by this study. However, these types of studies are needed if the recommendations of WHO to make cost-benefit analyses of introducing iodine fortification programmes in developed countries are to be fulfilled. We can only speculate on the
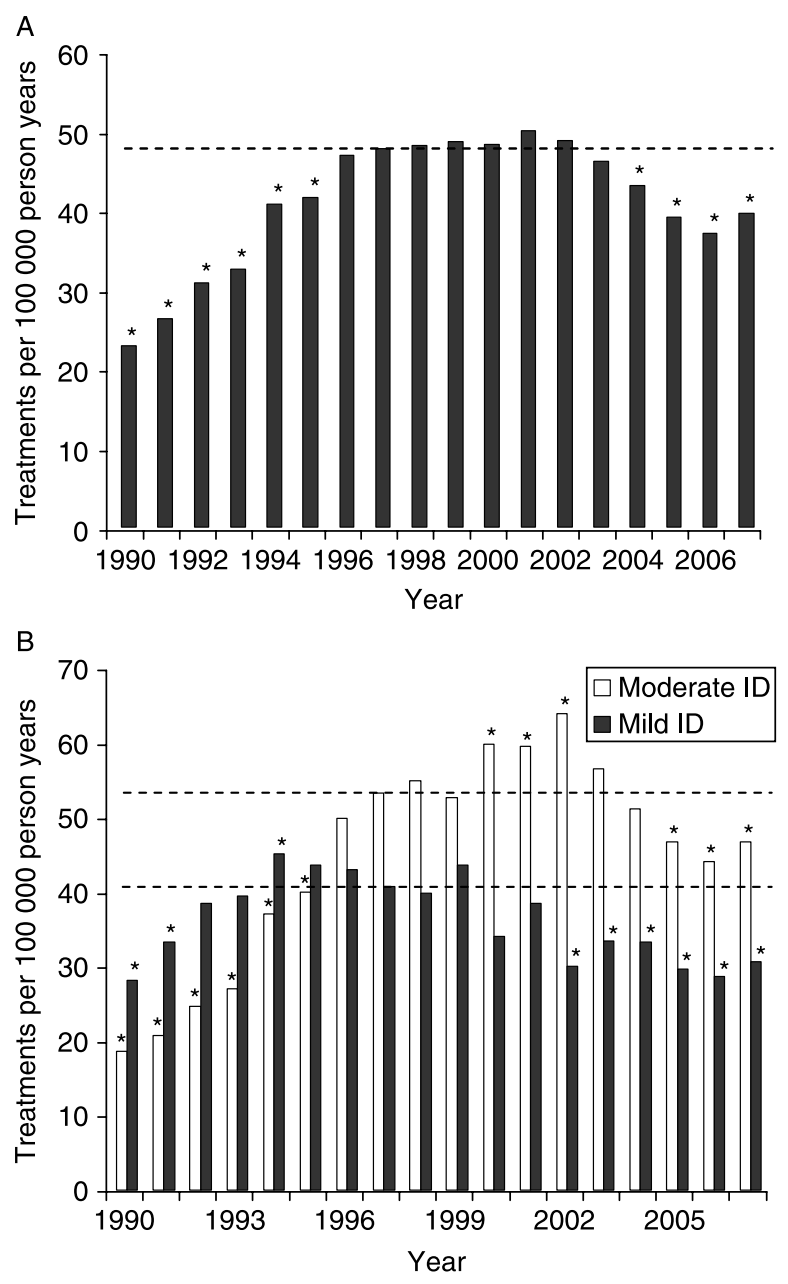

Figure 3 Radioiodine. (A) Nationwide, annual rates of radioiodine treatments for benign thyroid diseases. (B) Annual rates of radioiodine treatments for benign thyroid diseases split by region of prior mild or moderate iodine deficiency (ID). The rate in 1997 has been marked by a broken line for easier comparison. *Significant difference between the rate in the investigated year and the rate in $1997(P<0.05)$.

increased use of radioiodine treatment in the first part of the 1990's, but it could be due to changes in the treatment preferences of the physicians, as radioiodine was introduced as treatment of non-toxic nodular goitre in several European countries, including Denmark $(5,11)$. It could, however, also be the result of other factors such as higher diagnostic activity of thyroid disease.

It seems that radioiodine was not used as an alternative to thyroid operations as surgery rates were very stable, and it may well be that more persons chose to undergo treatment when having a non-surgical treatment option. On the other hand, the temporary increase in the use of radioiodine in the western region in the early years after iodization could be due to iodineinduced hyperthyroidism, as the incidence of hyperthyroidism increased temporarily after initiation of 
iodine fortification, especially in the area of moderate ID before iodization $(7,8)$. From this interpretation, it follows that the decrease seen in the eastern region may not have occurred, and that the increase seen in the western region in the 1990's might have continued, had it not been for the introduction of iodization.

The increase could also be caused by the physicians being more alert to the presence of thyroid disorders, and thus, by a more liberal use of diagnostic tests. In Denmark, there has been a steady increase in the number of tests used in the years studied (7). However, this could only explain the increase in the area of prior moderate ID, not the subsequent decline in that area, nor the steady decline in the eastern area. Indeed, the increase in testing might have led to an underestimation of the 'true' decline.

The use of radioiodine following iodization was highly dependent on prior iodine intake with a temporary bulge in treatment only in the moderately iodinedeficient region, probably as a result of treatment of iodine-induced hyperthyroidism. The same pattern was observed in an earlier study on the incident use of antithyroid medication (8). This variation supports the role of iodine as a causal factor behind the variation observed and against it being only the result of spontaneous variation.

In the present study, we analyzed the number of radioiodine doses given, not the number of patients treated. As high dietary iodine intake is associated with a low thyroid radioiodine uptake, it could be speculated that more patients needed two or more treatments after iodization than before, which would underestimate the decrease, if analyzed as the number of patients. On the other hand, radioactive iodine was no longer a treatment option for some patients with non-toxic goitre due to lower iodine uptake, and even though most of these patients were probably operated, some patients may have chosen to refrain from treatment altogether. Another potential source for overestimation of the rates of radioiodine treatment is the lack of age adjustment, as the mean age of the Danish population is known to have increased over time in the study period. If we had left out age adjustment in the analyses of surgery rates, we would have overestimated the rates in the last 5 years by about $3 \%$.

In contrast to radioiodine, surgery rates were more stable in this period. The type of operation chosen by the surgeons, though, changed towards an increased use of total thyroidectomies for benign thyroid disease during the later years. This could have been the result of more difficulties in treating hyperthyroidism with antithyroid medication after iodization, but it is more likely the result of a change of attitude among physicians (16-18).

Surgery is normally recommended when a patient presents a large or compressive goitre, or when malignancy cannot be ruled out, a common situation in the evaluation of thyroid nodules. Two-thirds of the operations analyzed in this study were procedures usually performed when facing a solitary nodule, possibly with continued suspicion of malignancy after biopsy (lobectomies or solely unilateral resections). Before iodization, $32 \%$ of a general adult Danish population (41-71 years) were found to have one or more thyroid nodules at ultrasound investigation (19). The increased use of ultrasound examination in the clinical evaluation of patients causes more of these nodules to be detected (20). The percentage of thyroid glands with nodularity have not decreased after iodization in Denmark (6), and it could be speculated that we have to wait for future generations to grow up in an iodine-sufficient environment, without developing thyroid enlargement and nodularity, before we will see a substantial decrease in the rate of surgery. In Sweden, iodine fortification of salt was started in 1936 and augmented in 1966 (21). Thyroid surgery rates in Sweden are $12-36 \%$ lower than in Denmark, and the rate of radioiodine treatment is almost half of the rate in Denmark (22).

The aim of the Danish iodization programme was to increase the iodine intake of the average Dane by $50 \mu \mathrm{g} / \mathrm{day}$. The median urinary iodine excretion in spot urine samples estimated in the population after the introduction of iodization indicates that the introduction is only sufficient in the eastern region and that the western region remains mildly iodine deficient. To achieve the full benefit of the iodization, it may be necessary to increase the amount of iodine added.

A pertinent question is how much an enlarged thyroid gland is able to regress. This question has not been fully answered, especially if the tissue has undergone nodular change. Statements vary from limited regression at least in adulthood (23-26), to widely reversible in young children $(25,27-29)$, and widely reversible even late in life (up to 65 years) (30). In Denmark, the prevalence of thyroid enlargement in adults decreased after iodization, as mentioned in the introduction. Also, the prevalence of large goitres, $>50 \mathrm{ml}$, declined from 1.68 to $0.89 \%$ (6). Thus, it seems that at least in Denmark, goitres, and even large goitres, were widely reversible. A cohort effect cannot be excluded though, since the study represents two crosssectional studies and not a follow-up study on the same persons. Furthermore, it may be that the decrease in thyroid size in absolute numbers (ml) was too small to affect the rate of treatment such as surgery and radioactive iodine.

As for other observational studies, there are limitations for this study, and a causal relationship cannot be proven. However, if these changes over time were due merely to changes in treatment policy, one would expect the changes to be similar in western and eastern Denmark. Moreover, the fact that the same pattern of changes was seen for antithyroid medication supports the association to the increased iodine intake and not just the result of changes in the choice between 
treatment options. A strong limitation is that we were not able to analyze the effect of other important factors for the development of thyroid growth and disease, such as smoking, alcohol intake, use of certain drugs and other goitrogens in the environment. Furthermore, the iodine content in milk is known to have increased in Denmark from 1990 to 2000 (31). These factors may have affected the iodine intake of the population, and thus influence and even mask the effect of the fortification programme. Finally, the study could not detect undiagnosed and untreated thyroid dysfunction.

In conclusion, this study showed that iodization seemed to be associated with a decrease in the use of radioiodine treatment, after a small, temporary increase in the area with moderate ID before iodine fortification. Even though earlier studies have shown a regression in thyroid size after iodization, this regression in size may be too small to result in a decrease in the use of surgery. Apparently, around two-thirds of operations were performed because of solitary nodules. As the prevalence of nodules has not decreased after iodization, it may take decades before the positive effects of iodization become evident with regard to the surgical treatment.

Iodization should still be regarded as a preventive measure to avoid future thyroid enlargement and other ID disorders and not as treatment for existing disease; yet it seems that some beneficial effects take less time to emerge.

\section{Declaration of interest}

The authors declare that there is no conflict of interest that could be perceived as prejudicing the impartiality of the research reported.

\section{Funding}

This study was part of the Danish Investigation on Iodine Intake and Thyroid Diseases (DanThyr), which is supported by grants from the Danish Medical Foundation, the 1991 Pharmacy Foundation, North Jutland County Research Foundation, Tømmerhandler Wilhelm Bangs Foundation, Copenhagen Hospital Corporation Research Foundation, the Danish Food Industry Agency and the Danish Agency for Science Technology and Innovation (grant number 2101-06-0065).

\section{Acknowledgements}

We thank the National Institute of Radiation Protection for delivering data that made this study possible.

\section{References}

1 World Health Organization. The United Nations Children's Fund and International Council for the Control of Iodine Deficiency Disorders. In Assessment of Iodine Deficiency Disorders and Monitoring their Elimination, 3rd edn. Geneva: World Health Organization, 2008.
2 Laurberg P, Pedersen KM, Hreidarsson A, Sigfusson N, Iversen E \& Knudsen PR. Iodine intake and the pattern of thyroid disorders: a comparative epidemiological study of thyroid abnormalities in the elderly in Iceland and in Jutland, Denmark. Journal of Clinical Endocrinology and Metabolism $1998 \mathbf{8 3}$ 765-769.

3 Delange F, de Benoist B, Pretell E \& Dunn JT. Iodine deficiency in the world: where do we stand at the turn of the century? Thyroid 200111 437-447.

4 Burgi $\mathrm{H}$, Kohler $\mathrm{M}$ \& Morselli B. Thyrotoxicosis incidence in Switzerland and benefit of improved iodine supply. Lancet 1998 3521034.

5 Bonnema SJ, Bennedbaek FN, Wiersinga WM \& Hegedus L. Management of the nontoxic multinodular goitre: a European questionnaire study. Clinical Endocrinology 2000 53 5-12.

6 Vejbjerg P, Knudsen N, Perrild H, Carle A, Laurberg P, Pedersen IB, Rasmussen LB, Ovesen L \& Jorgensen T. Effect of a mandatory iodization program on thyroid gland volume based on individuals' age, gender, and preceding severity of dietary iodine deficiency: a prospective, population-based study. Journal of Clinical Endocrinology and Metabolism 200792 1397-1401.

7 Bulow PI, Laurberg P, Knudsen N, Jorgensen T, Perrild H, Ovesen L \& Rasmussen LB. Increase in incidence of hyperthyroidism predominantly occurs in young people after iodine fortification of salt in Denmark. Journal of Clinical Endocrinology and Metabolism 200691 3830-3834.

8 Cerqueira C, Knudsen N, Ovesen L, Perrild H, Rasmussen LB, Laurberg P \& Jorgensen T. Association of iodine fortification with incident use of antithyroid medication - a Danish Nationwide Study. Journal of Clinical Endocrinology and Metabolism $2009 \mathbf{9 4}$ 2400-2405.

9 Andersen TF, Madsen M, Jorgensen J, Mellemkjoer L \& Olsen JH. The Danish National Hospital Register. A valuable source of data for modern health sciences. Danish Medical Bulletin 199946 263-268.

10 Ovretveit J. Nordic privatization and private healthcare. International Journal of Health Planning and Management 200318 233-246.

11 Bonnema SJ, Bennedbaek FN \& Hegedus L. Danish endocrinologists' examination and treatment of non-toxic multinodular goiter. A questionnaire study. Ugeskrift for Laeger $2001 \mathbf{1 6 3}$ 1265-1269.

12 Pedersen KM, Laurberg P, Nohr S, Jorgensen A \& Andersen S. Iodine in drinking water varies by more than 100-fold in Denmark. Importance for iodine content of infant formulas. European Journal of Endocrinology 1999140 400-403.

13 Rasmussen LB, Ovesen L, Bulow I, Jorgensen T, Knudsen N, Laurberg P \& Perrild H. Dietary iodine intake and urinary iodine excretion in a Danish population: effect of geography, supplements and food choice. British Journal of Nutrition 2002 87 61-69.

14 Rasmussen LB, Carle A, Jorgensen T, Knudsen N, Laurberg P, Pedersen IB, Perrild H, Vejbjerg P \& Ovesen L. Iodine intake before and after mandatory iodization in Denmark: results from the Danish Investigation of Iodine Intake and Thyroid Diseases (DanThyr) study. British Journal of Nutrition 2008100 1-8.

15 Pedersen KM, Nohr SB \& Laurberg P. Iodine intake in Denmark. Ugeskrift for Laeger 1997159 2201-2206.

16 Korun N, Asci C, Yilmazlar T, Duman H, Zorluoglu A, Tuncel E, Erturk E \& Yerci O. Total thyroidectomy or lobectomy in benign nodular disease of the thyroid: changing trends in surgery. International Surgery 199782 417-419.

17 Bellantone R, Lombardi CP, Bossola M, Boscherini M, De Crea C, Alesina P, Traini E, Princi P \& Raffaelli M. Total thyroidectomy for management of benign thyroid disease: review of 526 cases. World Journal of Surgery 200226 1468-1471.

18 Pappalardo G, Guadalaxara A, Frattaroli FM, Illomei G \& Falaschi P. Total compared with subtotal thyroidectomy in benign nodular disease: personal series and review of published reports. European Journal of Surgery $1998 \mathbf{1 6 4}$ 501-506. 
19 Knudsen N, Perrild H, Christiansen E, Rasmussen S, DigePetersen $\mathrm{H}$ \& Jorgensen T. Thyroid structure and size and twoyear follow-up of solitary cold thyroid nodules in an unselected population with borderline iodine deficiency. European Journal of Endocrinology 2000142 224-230.

20 Wiest PW, Hartshorne MF, Inskip PD, Crooks LA, Vela BS, Telepak RJ, Williamson MR, Blumhardt R, Bauman JM \& Tekkel M. Thyroid palpation versus high-resolution thyroid ultrasonography in the detection of nodules. Journal of Ultrasound in Medicine 199817 487-496.

21 Petersen K, Lindstedt G, Lundberg PA, Bengtsson C, Lapidus L \& Nystrom E. Thyroid disease in middle-aged and elderly Swedish women: thyroid-related hormones, thyroid dysfunction and goitre in relation to age and smoking. Journal of Internal Medicine 1991 229 407-413.

22 Haskå T. The Trend in Radioiodine Therapy for Benign Thyroid Diseases in Denmark 1980 to 2006. Denmark: National Institute of Radiation Protection, 2008.

23 Aghini-Lombardi F, Antonangeli L, Pinchera A, Leoli F, Rago T, Bartolomei AM \& Vitti P. Effect of iodized salt on thyroid volume of children living in an area previously characterized by moderate iodine deficiency. Journal of Clinical Endocrinology and Metabolism 199782 1136-1139.

24 Zimmermann MB, Hess SY, Adou P, Toresanni T, Wegmuller R \& Hurrell RF. Thyroid size and goiter prevalence after introduction of iodized salt: a 5-y prospective study in schoolchildren in Cote d'Ivoire. American Journal of Clinical Nutrition 200377 663-667.

25 Lind P, Kumnig G, Heinisch M, Igerc I, Mikosch P, Gallowitsch HJ, Kresnik E, Gomez I, Unterweger O \& Aigner H. Iodine supplementation in Austria: methods and results. Thyroid 2002 12 903-907.
26 Heinisch M, Kumnig G, Asbock D, Mikosch P, Gallowitsch HJ, Kresnik E, Gomez I, Unterweger O \& Lind P. Goiter prevalence and urinary iodide excretion in a formerly iodine-deficient region after introduction of statutory lodization of common salt. Thyroid 2002 12 809-814.

27 Zimmermann M, Adou P, Torresani T, Zeder C \& Hurrell R. Low dose oral iodized oil for control of iodine deficiency in children. British Journal of Nutrition $2000 \mathbf{8 4} 139-141$.

28 Hess SY, Zimmermann MB, Torresani T, Burgi H \& Hurrell RF. Monitoring the adequacy of salt iodization in Switzerland: a national study of school children and pregnant women. European Journal of Clinical Nutrition 200155 162-166.

29 Azizi F, Mehran L, Sheikholeslam R, Ordookhani A, Naghavi M, Hedayati M, Padyab M \& Mirmiran P. Sustainability of a wellmonitored salt iodization program in Iran: marked reduction in goiter prevalence and eventual normalization of urinary iodine concentrations without alteration in iodine content of salt. Journal of Endocrinological Investigation 200831 422-431.

30 Knudsen N, Bulow I, Jorgensen T, Laurberg P, Ovesen L \& Perrild H. Goitre prevalence and thyroid abnormalities at ultrasonography: a comparative epidemiological study in two regions with slightly different iodine status. Clinical Endocrinology 200053 479-485.

31 Rasmussen LB, Larsen EH \& Ovesen L. Iodine content in drinking water and other beverages in Denmark. European Journal of Clinical Nutrition $2000 \mathbf{5 4} 57-60$.

Received 11 January 2010

Accepted 17 January 2010 